\title{
Optimization of sorting efficiency of size grading machine using oscillating sieve with swing along width direction
}

\author{
Thatchapol Chungcharoena, Warunee Limmun, Watcharapong Chanpaka and Naruebodee Srisang \\ Engineering Department, King Mongkut's Institute of Technology Ladkrabang, Prince of Chumphon Campus, Chumphon, Thailand
}

\begin{abstract}
Grading according to the sizes is an important value adding technique for Robusta green coffee bean. Mechanical grading can increase the sorting efficiency and the need for workers is decreased. Therefore, the sorting efficiency of size grading machine was optimized based on inclined angle and oscillating speed. The Response Surface Methodology (RSM) combined with central composite design (CCD) was applied in the optimization of the sorting efficiency of the machine. A quadratic model was suggested for the sorting efficiency of size grading machine. The results showed that the optimum operating parameters for size grading machine using oscillating sieve with swing along width direction were inclined angle of 5.06 degree and oscillating speed of $183.28 \mathrm{rpm}$ with a sorting efficiency of $79.99 \%$. The high correlation coefficient $\left(\mathrm{R}^{2}\right.$ $=0.9676$ ) indicated that the data predicted using RSM were in good agreement with the experimental results.
\end{abstract}

\section{Introduction}

Size grading is one of the important operations in the production of green coffee bean because the size directly affected the time and temperature in the roasting process [1]. Moreover, it also affects the qualities (taste and odor) and value of green coffee bean [2]. Generally, the size of green coffee bean in Thailand can be divided into four groups based on diameter of the individual coffee bean according to the standard of Ministry of Agriculture and Cooperatives, Thailand [3] such as very large, large, medium and small. Theirs diameters were as follows: the diameter of very large size must be not less than $7.1 \mathrm{~mm}$; the diameter of large size must be not less than $6.3 \mathrm{~mm}$ and not more than $7.0 \mathrm{~mm}$; the diameter of medium size must be not less than $5.6 \mathrm{~mm}$ and not more than $6.2 \mathrm{~mm}$ and the diameter of small size must be not more than 5.5 $\mathrm{mm}$.

Nowadays, commercial size grading of green coffee bean is performed by the size grading machine using oscillating sieve with swing along length direction. This size grading machine has the low sorting efficiency because the green coffee beans were moved in the same direction with oscillating sieve. This provides the slight distribution of green coffee bean and green coffee bean press. Some green coffee beans are stuck on the sieve, leading to low sorting efficiency. One of possible methods that increase the distribution of green coffee bean can be done by using oscillating sieve with swing along width direction. The sieve is perpendicularly moved with green coffee bean. This would provide the good distribution of green coffee bean, leading to lower green coffee bean press and resulting in the higher sorting efficiency. There are two important factors which affected the sorting efficiency of size grading machine using oscillating sieve with swing along width direction such as inclined angle and oscillating speed. However, there are no reports on the optimization of the sorting efficiency which depended on the inclined angle and oscillating speed.

Therefore, the objective of this work was to investigate the optimization of size grading factors (inclined angle and oscillating speed) using Response Surface Methodology (RSM) for sorting efficiency of size grading machine using oscillating sieve with swing along width direction.

\section{Materials and Methods}

\subsection{Materials}

Robusta green coffee bean without grading was purchased from Coffee Chumphon Provincial Cooperative, Chumphon, Thailand. Its initial moisture content is $13 \%$ wet basis (w.b.). The Robusta green coffee bean was graded by size into four groups using the vibrating screening with standard sieves such as very large size (XL), large size (L), medium size (M) and small size (S). Each group was painted with different color as shown in Figure 1.

\subsection{Experimental design for optimization}

A two-factor-two-level central composite design (CCD) with Minitab version 18 was used for grading process. The input variables and their coded and uncoded values are shown in Table 1.

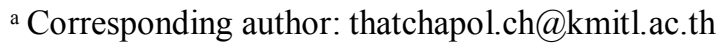




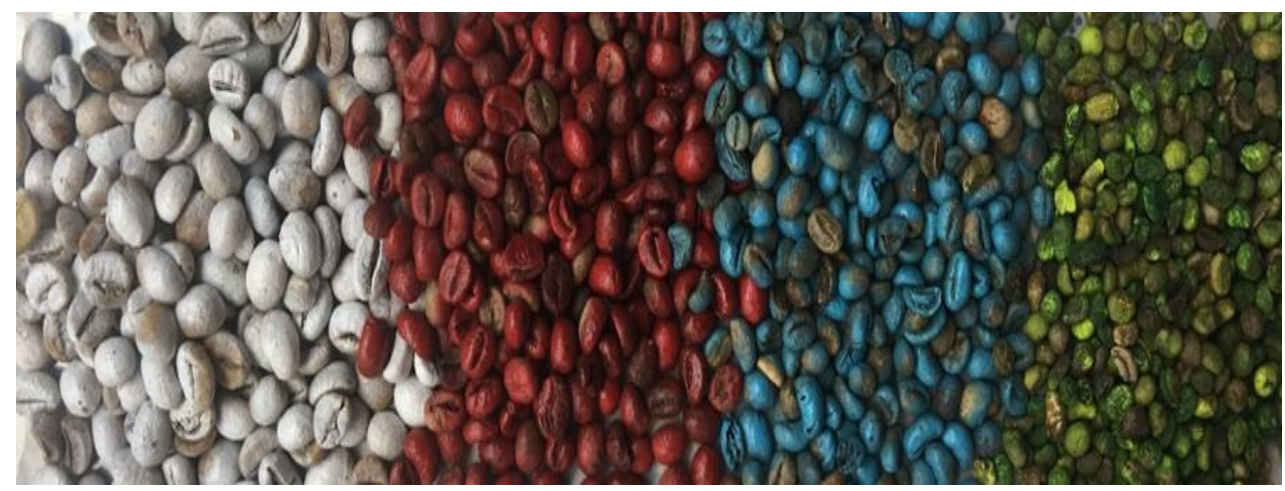

very large size

(XL) large size

(L) medium size

(M) small size

(S)

Figure 1. Robusta green coffee bean with different color

Table 1. Levels of grading process variables employed for this study

\begin{tabular}{|c|c|c|c|c|c|}
\hline \multirow[b]{2}{*}{ Variable } & \multirow[b]{2}{*}{ Coding } & \multirow[b]{2}{*}{ Units } & \multicolumn{3}{|c|}{ Levels } \\
\hline & & & -1 & 0 & 1 \\
\hline Inclined angle & $\mathrm{X}_{1}$ & degree & 4.5 & 5 & 5.5 \\
\hline Oscillating speed & $\mathrm{X}_{2}$ & $\mathrm{rpm}$ & 175 & 185 & 195 \\
\hline
\end{tabular}

The response variable (sorting efficiency) was fitted a second-order polynomial equation in order to correlate the response variable to the independent variable (inclined angle and oscillating speed). It was represented by a polynomial quadratic equation as follows [5]:

$\mathrm{Y}=\beta_{0}+\beta_{1} \mathrm{X}_{1}+\beta_{2} \mathrm{X}_{2}+\beta_{11} \mathrm{X}_{1}{ }^{2}+\beta_{22} \mathrm{X}_{2}^{2}+\beta_{12} \mathrm{X}_{1} \quad \mathrm{X}_{2}$ (1)

where $\mathrm{Y}$ is the sorting efficiency; $\mathrm{X}_{1}$ is the inclined angle; $\mathrm{X}_{2}$ is the oscillating speed; $\beta_{0}$ is the intercept value; $\beta_{1}$ and $\beta_{2}$ are linear value; $\beta_{12}$ is interaction value; and $\beta_{11}$ and $\beta_{22}$ are quadratic values.

\subsection{Size grading process}

A size grading machine using oscillating sieve with swing along width direction was used to screen the size of Robusta green coffee bean as presented by schematic diagram in Figure 2. It consisted of four oscillating sieves with difference hole sizes (4, 5, 6 and $7 \mathrm{~mm})$. All sieves were oscillated using a camshaft which was driven by a 1HP motor. A brush was installed on each sieve to prevent the stuck coffee bean during oscillation. $500 \mathrm{~g}$ of each Robusta green coffee bean group was well-mixed as a sample (total sample of $2 \mathrm{~kg}$ ) and fed into the grader at feed rate of $30 \mathrm{~kg} / \mathrm{h}$. The experiment conditions were set at inclined angles of $4-6^{\circ}$ and oscillating revolution speeds of 170-200 rpm. The oscillating sieve could separate the Robusta green coffee bean as four sizes viz., size I (very large size, $>7.1 \mathrm{~mm}$ ), size II (large size, $6.3-$ $7 \mathrm{~mm}$ ), size III (medium size, $5.6-6.2 \mathrm{~mm}$ ) and grade IV (small size, $<5.5 \mathrm{~mm}$ ). When no Robusta green coffee bean was observed in the oscillating sieve, the mass of Robusta green coffee bean from each outlet were removed and weighed for calculating the sorting efficiency.

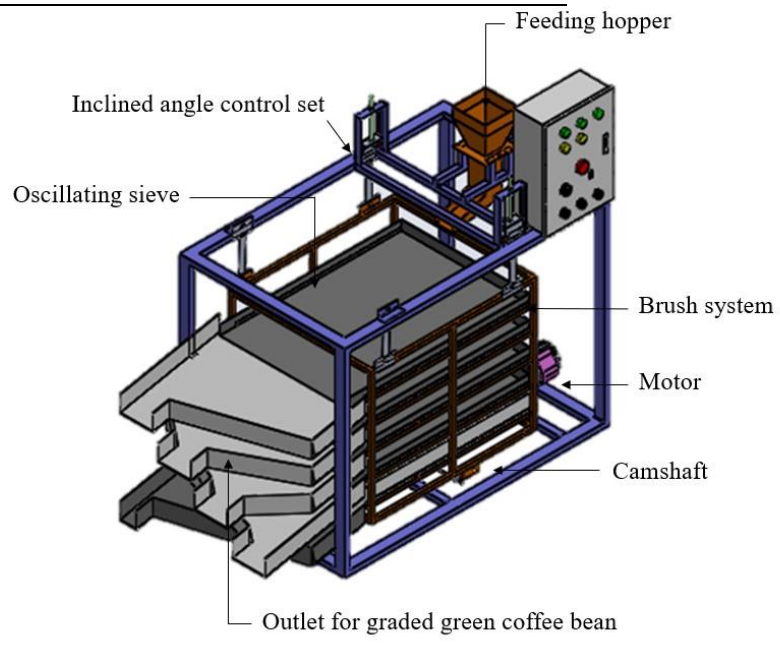

Figure 2. Schematic diagram of size grading machine using oscillating sieve with swing along width direction.

\subsection{Analysis of the samples}

The sorting efficiency was determined by the standard method reported by Tabatabaekoloor and Hashemi [6]. The \%sorting efficiency was calculated using Eq. (2):

$$
E_{W}=\frac{\sum P_{g i} W_{i} G_{i}}{Q P_{i}}
$$

Where,

EW size grading efficiency (\%)

Pgi fraction of green coffee bean size $\mathrm{i}$ tototal green coffee bean dropping into receiving tray size $i$

$\mathrm{W}_{\mathrm{i}} \quad$ fraction of green coffee bean size $\mathrm{i}$ at the beginning of sizing to total green coffee bean at the beginning of sizing 
Gi outflow rate of green coffee bean size $\mathrm{i}$ $(\mathrm{kg} / \mathrm{h})$

Pi fraction of size i to total green coffee bean at the beginning of sizing

Q feed rate $(\mathrm{kg} / \mathrm{h})$

Table 2. The design experiment matrix based on central composite design (CCD).

\begin{tabular}{cccc}
\hline \multirow{2}{*}{ Runs } & \multicolumn{2}{c}{ Variable } & \multirow{2}{*}{ Response, $Y$} \\
\cline { 2 - 3 } & $\mathrm{X}_{1}$ & $\mathrm{X}_{2}$ & \\
\hline 1 & 4.65 & 177.93 & 74.83 \\
2 & 5.35 & 177.93 & 77.68 \\
3 & 4.65 & 192.07 & 75.03 \\
4 & 5.35 & 192.07 & 73.5 \\
5 & 4.50 & 185.00 & 74.26 \\
6 & 5.50 & 185.00 & 76.3 \\
7 & 5.00 & 175.00 & 76.63 \\
8 & 5.00 & 195.00 & 74.38 \\
9 & 5.00 & 185.00 & 79.07 \\
10 & 5.00 & 185.00 & 80.16 \\
11 & 5.00 & 185.00 & 80.7 \\
12 & 5.00 & 185.00 & 79.08 \\
13 & 5.00 & 185.00 & 80.18 \\
\hline
\end{tabular}

\section{Results and Discussion}

\subsection{Data analysis}

The results obtained from all the variables (inclined angle and oscillating speed) are showed in Table 2 . The model achieved using the experiments results were designed using RSM combined with CCD shown in Eq. (3).

$$
\begin{gathered}
Y=-2,277+267.5 X_{1}+18.34 X_{2}-18.50 X_{1}^{2}- \\
0.04399 X_{2}^{2}-0.438 X_{1} X_{2} ; R^{2}=0.9676
\end{gathered}
$$

The value of determination coefficient (R2) for the model was found to be 0.96 , which indicates the good fitness of the model. The predicted R2 was 0.9197 which also corroborates the reliability of the model. The statistical significance of model was evaluated using the Fisher test (F test) for ANOVA which was listed in Table 3. The model F-value of 41.80 implies the model is statistically significant at the $95 \%$ confidence level. Moreover, the lack of fit was found to be insignificant; thus indicating divergence of the observed value from the predicted value. In addition, the inclined angle and oscillating speed significantly affected the sorting efficiency as shown in Table 3.

Table 3. ANOVA for model regression for sorting efficiency of size grading machine.

\begin{tabular}{lccccc}
\hline Source & $\begin{array}{c}\text { Sum of } \\
\text { Square }\end{array}$ & DF & $\begin{array}{c}\text { Mean } \\
\text { Square }\end{array}$ & F-Value & Significance Level \\
\hline Model & 76.10 & 5 & 15.22 & 41.80 & $0.000^{* *}$ \\
$\mathrm{X}_{1}$ & 2.21 & 1 & 2.21 & 6.07 & $0.043^{* *}$ \\
$\mathrm{X}_{2}$ & 6.41 & 1 & 6.41 & 17.61 & $0.004^{* *}$ \\
$\mathrm{X}_{1}{ }^{*} \mathrm{X}_{2}$ & 4.79 & 1 & 4.79 & 13.17 & $0.008^{* *}$ \\
$\mathrm{X}_{1}{ }^{2}$ & 37.19 & 1 & 37.19 & 102.13 & $0.000^{* *}$ \\
$\mathrm{X}_{2}{ }^{2}$ & 33.66 & 1 & 33.66 & 92.43 & $0.000^{* *}$ \\
Residual & 2.55 & 7 & 0.36 & & \\
Lack of Fit & 0.42 & 3 & 0.14 & 0.26 & $0.849^{*}$ \\
Pure Error & 2.13 & 4 & 0.53 & & \\
Total & 78.65 & 12 & & & \\
\hline
\end{tabular}

experimental values, demonstrating that the proposed

\subsection{Effect of process variables}

Figure 3 shows the interactions between sorting efficiency and independent variables (inclined angle and oscillating speed). When the inclined angle and oscillating speed were increased, the sorting efficiency was increased. However, these trends were reversed when the inclined angle and oscillating speed reached a certain value. This could be explained that too much inclined angle and oscillating speed would lead to excess movement speed of green coffee bean, leading to the higher incorrect category dropping, and resulting in the decrease of size grading efficiency $[7,8]$.

\subsection{Validation of models}

The models obtained for sorting efficiency was validated by comparing experimental values with the predicted values from the test as shown in Figure 4. The result showed that the predicted values were close to the model is credible for expressing the correlation between the effective parameters and the sorting efficiency.

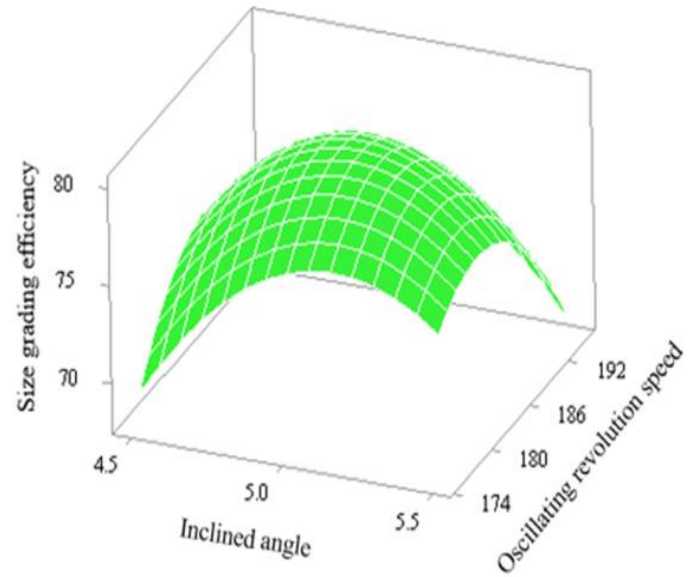

Figure 3. Sorting efficiency against inclined angle and oscillating speed. 


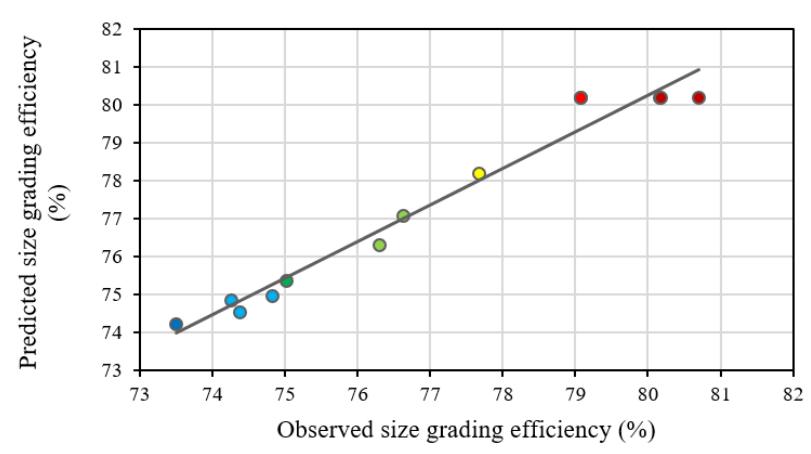

Figure 4. Predicted values against observed values.

\section{Conclusions}

Based on data analysis with Response Surface Method, Optimum values of 5.06 degree and $183.28 \mathrm{rpm}$ were obtained for inclined angle and oscillating speed respectively. The sorting efficiency was found to have optimum value of $79.99 \%$ with desirability of 0.9676 . The inclined angle and oscillating speed were found to greatly affect the grading process of Robusta green coffee bean. The models obtained for the grading process was adjudged to adequately describe the observations.

\section{Acknowledgement}

The authors express the sincere appreciation to the King Mongkut's Institute of Technology Ladkrabang (KREF016003) for supporting the study financially.

\section{References}

1. Vaast P, Bertrand B, Perriot J J, Guyot B and Genard M 2006 Fruit thinning and shade improve bean characteristics and beverage quality of coffee (Coffea arabica L.) under optimal conditions J. Sci. Food Agric. 86 197-402

2. Leroy T, Ribeyre F, Bertrand B, Charmetant P, Dufour M, Montagnon C, Marraccini P and Pot D 2006 Genetics in coffee quality Braz. J. Plant Physiol. 18 229-242

3. The Ministry of Agriculture and Cooperatives 2009 Thai Agricultural standard: Robusta coffee bean (TAS 5700-2009), The Royal Gazette, Thailand

4. Srisang N, Chanpaka1 W and Chungcharoen T 2019 Proc. Int. Conf. On The 12th Thai Society of Agricultural Engineering International Conference, March 13-15, Chonburi, Thailand

5. Arteaga G E, Li-Chan E, Vazquez-Arteaga M C and Nakai S 1994 Systematic experimental designs for product formula optimization Trends Food Sci. Technol. 5 243-254

6. Tabatabaekoloor R and Hashemi J 2008 Development and Evaluation of a citrus sorting machine with rotary semi-conical disc J. Agric. Machin. Sci. 4 371-374

7. Preetha P, Pandiselvam R, Deepa J and Varadharaju N 2016 Development and performance evaluation of rotary drum grader for tomato Int. J. Agric. Environ. Biotechnol. 9 137-144

8. Gunathilake D M C C, Wasala W M C B and Palipane K B 2016 Design, development and evaluation of a size grading machine for onion Procedia Food Sci. 6 103-107 